\title{
Key Risk Factors Influencing Harbor Tugboat Operations for Kaohsiung Port
}

Wen-Jui Tseng

Department of Shipping and Transportation Management, National Kaohsiung University of Science and Technology, Kaohsiung, Taiwan, R.O.C.

Ji-Feng Ding

Department of Aviation and Maritime Transportation Management, Chang Jung Christian University, Tainan, Taiwan, R.O.C., jfding@mail.cjcu.edu.tw

Chia-Ming Liu

Department of Shipping and Transportation Management, National Kaohsiung University of Science and Technology, Kaohsiung, Taiwan, R.O.C.

Liou-Yuan Li

Department of International Business Administration, Rajamangala University of Technology Thanyaburi, Khlong Luang Pathum Thani, Thailand

Follow this and additional works at: https://jmstt.ntou.edu.tw/journal

Part of the Fresh Water Studies Commons, Marine Biology Commons, Ocean Engineering Commons, Oceanography Commons, and the Other Oceanography and Atmospheric Sciences and Meteorology Commons

\section{Recommended Citation}

Tseng, Wen-Jui; Ding, Ji-Feng; Liu, Chia-Ming; and Li, Liou-Yuan (2021) "Key Risk Factors Influencing Harbor Tugboat Operations for Kaohsiung Port," Journal of Marine Science and Technology. Vol. 29: Iss. 3, Article 10.

DOI: 10.51400/2709-6998.1439

Available at: https://jmstt.ntou.edu.tw/journal/vol29/iss3/10

This Research Article is brought to you for free and open access by Journal of Marine Science and Technology. It has been accepted for inclusion in Journal of Marine Science and Technology by an authorized editor of Journal of Marine Science and Technology. 


\title{
RESEARCH ARTICLE \\ Key Risk Factors Influencing Harbor Tugboat Operations for Kaohsiung Port
}

\author{
Wen-Jui Tseng ${ }^{a}$, Ji-Feng Ding ${ }^{b, *}$, Chia-Ming Liu ${ }^{a}$, Liou-Yuan Li $^{c}$ \\ ${ }^{a}$ Department of Shipping and Transportation Management, National Kaohsiung University of Science and Technology, Kaohsiung, \\ 81157, Taiwan, ROC \\ ${ }^{\mathrm{b}}$ Department of Aviation and Maritime Transportation Management, Chang Jung Christian University, Tainan, 71101, Taiwan, ROC \\ ${ }^{c}$ Department of International Business Administration, Rajamangala University of Technology Thanyaburi, 39 Moo 1, Klong6, Khlong \\ Luang, Pathum Thani, 12110, Thailand
}

\begin{abstract}
The harbor tugboat operation is a very important business and process of Kaohsiung port. To ensure the safety of harbor tugboat operations and to reduce the occurrence of accidents, it is an important issue to conduct a risk assessment of tugboat operations for Kaohsiung port. Hence, the main purpose of this paper is employ the analytic hierarchy process (AHP) method to evaluate key risk factors influencing the harbor tugboat operations for Kaohsiung port. At first, a total of three evaluation dimensions with 14 preliminary risk factors are generated from literature and interviews of tugboat captains. We then applied the steps of AHP method and AHP experts' questionnaires to evaluate the key risk factors. The empirical results showed that: (1) 'Tugboat operators' is the most important risk evaluation dimension influencing harbor tugboat operations for Kaohsiung port in Taiwan. (2) In order of relative importance, The top six key risk factors influencing the harbor tugboat operations for Kaohsiung port are "judgment error," "work fatigue," "poor skills," "communication misunderstanding," "negligence of the relative motion between tugboats and commercial ships," and "personality factors," respectively. Furthermore, some recommendations concerning effective risk management strategies and advices are provided for harbor tugboat practitioners.
\end{abstract}

Keywords: Risk, Harbor tugboat operation, Kaohsiung port, Analytic hierarchy process (AHP)

\section{Introduction}

$\mathrm{T}$ he port is where the land transportation and the water transportation are connected, and mainly provides services for ships, passengers, and cargos. It can be a distribution center for domestic and foreign trade goods, or a transshipment station between marine transportation and land transportation, which makes it essentially a marine terminal. Therefore, in order to demonstrate the advantages of ports [19] in terms of business functions, industrial functions, transshipment functions, and value-added service functions, cooperation among a port's operation system (including ship entry and exit, harbor tugboat operations, port navigation, ship parking, etc.), the terminal loading and unloading operation system (including equipment dispatch, manual dispatch operations, etc.), the warehousing operation system (including cabin arrangement, cargo entry, etc.), and the land and marine service systems (including the external 
transportation system) is required. In short, the port serves as the hub of a maritime shipping chain [17], a cargo transshipment and distribution center, and a link between ships and other means of transportation.

The harbor tugboat operation $[9,10,23]$ is a very important business and process among port systems, as it determines the smoothness of ship entry and exit, and even the mooring safety of ships. Therefore, the service quality and operational efficiency of harbor tugboat operations play a very important role in the loading and unloading operation services of the ship entry and exit of shipping companies. In addition, considering that an increasing number of ships have become larger in recent years, harbor tugboat operations pose certain operational risks for ship entry and exit, as well as docking operations[10]. Accidents arising from unsafe harbor tugboat operations will affect the performance and competitiveness of the port. Therefore, how to ensure the safety of harbor tugboat operations and pay adequate attention to risk management [7] is an important business issue that cannot be ignored.

Taiwan has an economy surrounded by the sea (if the scale of the economy is represented by GDP, Taiwan ranks 21 in the world in 2019), and there is a causal relationship between a commercial port and its economic development [5]. For marine regions like Taiwan, the development of ports have decisive influence on its economic development [5]. In particular, Kaohsiung port is currently the largest commercial port in Taiwan, and more than $70 \%$ of container volume and more than $60 \%$ of Taiwan's foreign trade volume are imported and exported via Kaohsiung port. In 2019, the container handling volume of Kaohsiung port was 10.43 million TEUs, making Kaohsiung port the 15th largest container port in the world. Therefore, Kaohsiung port plays a significant role in transportation and logistics for Taiwan, which is mainly based on international trade. Moreover, Kaohsiung port is the most dangerous area for international commercial port navigation $[10,14]$ in western Taiwan. As ships become larger and quicker, in order to avoid the occurrence of more accidents in port [24] due to the increased traffic density, and build a safe and sound harbor tugboat operation environment for the port, harbor tugboat operations practitioners should strengthen their risk management [10], while the operational safety of harbor tugboat operations should be strictly controlled to maintain the loading and unloading safety of ships.
In recent years, Kaohsiung port has been handling an increasing number of ships with larger sizes, and the berthing entry and exit of the port have been increasingly fast and professional. When the docked berths are too densely distributed in the port $[9,10]$, ships may easily collide with each other, and even with the docks. In addition to the dangers facing personnel, ship, and cargo, a ship accident poses considerable threat to the port authority or terminal equipment, and leads to hidden dangers in the polluted sea areas. Therefore, the risk management of harbor tugboat operations is a topic worthy of research. In the past, most research focused on the tugboat scheduling [23], the operational efficiency and productivity of tugboats $[4,12,22]$, and the quality of tugboat services $[9,1,11]$; however, there is a lack of research on the risk management of harbor tugboat operations. To address the lack of research regarding the safety operations and risk management of harbor tugboat operations, this study conducts in-depth interviews on the actual practitioners of harbor tugboat operations, and then, analyzes the risk factors that may cause cargo damage in each operational phase of harbor tugboat operations through the risk management evaluation process.

In order to resolve the research issues arising from the above research motives, the main purpose of this paper is to explore the key risk factors influencing the harbor tugboat operations for Kaohsiung port. However, evaluating the risk factors influencing harbor tugboat operations involves many evaluation dimensions and criteria, and the scope and hierarchy of such operational risk factors are broad and complex. In addition, the analytic hierarchy process (AHP) [16] is a decision-making method that systematically solves complex problems, and is mainly used for solving decision-making problems with multiple attributes in uncertain situations. Therefore, to evaluate the relative weights of different risk factors, and then, obtain key risk factors, this paper adopts the AHP method and AHP expert questionnaires. It is intended that the results of this study can provide reference for industry and academia.

Specifically, this study first explored the risk factors that may cause cargo damage during the harbor tugboat operations of Kaohsiung port through the risk management evaluation process. Secondly, the key risk factors influencing the harbor tugboat operations of Kaohsiung port were determined through the AHP expert questionnaire, thus, facilitating the operators to focus on the key operational risk factors. Finally, the risk management strategies 
were developed as the basis for the feasible implementation of risk management strategies. The rest of this paper is organized as follows: The second section identifies preliminary risk factors, and the third section describes the AHP method. The fourth section consists of an empirical study, and the final section presents concluding remarks.

\section{Identification of preliminary risk factors}

Tugboats [23] assist ships in and out of the port (pushing toward the berthing dock or pulling or pushing away from the dock) and aids in the implementation of various unique tasks in the water areas of the port (such as mooring ships, water ships, dredgers, cleaning ships, firefighting ships). In addition, the operational characteristics of tugboats in port are different from those of generalpurpose ships, meaning tugboat operations are closely related to the safety of the shipping companies, cargo owners, practitioners, and ports. Furthermore, as a port is a restricted water area, the thrust of ship engines is too strong, which increases the required radius of gyration. After entering the port, ships must stop at an idle speed, and then, tugboats must be used for towing and pushing. Therefore, the dispatch and operational process of tugboats have become the most important part for the entry and exit of ships.

Since the ships entering and leaving the port are affected by ocean currents, weather, local environment, and terrain, it is necessary to assist them by pilots and tugboats. If the port is at its peak operation time, the entry and exit operations will be busier. In addition, as ships have no brake function, they must decelerate when entering or leaving the port, thus, it is necessary for tugboats to assist ships in sailing safely in the port [1]. Moreover, due to the rapid development of international marine trade and the advent of the larger and faster ships, the port is becoming more crowded. As the port where ships frequently enter and exit is the most crowded area of marine transport, if any ship or relevant personnel makes a slight mistake during operation, it will greatly increase the probability and severity of collision accidents $[9,10]$.

Since the collision of ships is a kind of marine accidents [14], its three most important factors include tugboat operators, ships, and environment $[9,10,7,14,2,8,20,21]$. Specifically, when maneuvering ships, tugboat operators must consider the internal factors of ships, such as rudder, anchor windlass, displacement ton, draught, and inertia effect, and also cope with external environmental factors, such as wind direction, tide, waves, and ocean environment. Additionally, according to the survey, $80 \%$ of the ship accidents that have occurred in Taiwan in recent years resulted from human errors $[14,13]$. Thus, how to effectively reduce human errors and prevent the recurrence of ship accidents is an important issue. To discuss the navigation safety of ships and the human factors influencing ship collision, this paper believes that the relationship among tugboat operators, ships, and environment should be considered, in order to reduce the operational risks of tugboats.

Sound risk management analysis [6,18] should include measurable indicators or criteria to accurately identify and evaluate the risks; therefore, this study recorded and initially developed the risk factors that may cause cargo damage in each operational phase of Kaohsiung port. In addition, after interviewing six public tugboat captains, chief mates and second mates in Kaohsiung port, the preliminary risk factors were further discussed and revised. Finally, three major risk evaluation dimensions and 14 important risk factors were initially concluded, as based on the key risk factors influencing the harbor tugboat operations of Kaohsiung port. The relevant characteristics are described below; and their codes are shown in parentheses.

1. The first risk dimension is "tugboat operators $\left(D_{1}\right)$," which refers to errors caused by the personal operation mishandling of tugboat operators or the misplaced interface between tugboat operators and others. Five risk factors $[9,10,7,2]$ can be summed to measure the "tugboat operators" dimension, as follows:

- Work fatigue $\left(F_{11}\right)$. Tugboat operators may be excessively fatigued due to irregular working hours, working overtime, abnormal work and rest balance, excessive stress, and lack of concentration, which may lead to accidents. Work fatigue may reduce mental, physical, and emotional management capabilities, including strength, speed, reaction time, coordination, decision-making capability, and balance.

- Judgment error $\left(F_{12}\right)$. Judgment errors can be caused by the abnormal mental state of tugboat operators, as affected by personal problems, or a lack of the correct concepts of tugboat operators. Personal problems, such as physical disability, family death or illness, marital relationship problems, health issues, financial issues, anger, or poor contact with ship partners may result in judgment errors. In addition, the lack of correct concepts may be due to the lack of crisis sense of tugboat operators, who may fail to correctly handle such problems, thus, missing the best 
processing time window and making an accident unavoidable.

- Poor skills $\left(F_{13}\right)$. Poor skills include insufficient work experience and skills that cannot be effectively improved due to the personal factors, learning willingness, lack of on-the-job training, or personnel transfer of tugboat operators.

- Personality factors $\left(F_{14}\right)$. Tugboat operators may ignore the existence of risk factors and reduce their ability to perform business due to the personality factors of tugboat operators, such as arrogance, irritability, suspicion, anxiety, and tension.

- Communication misunderstanding $\left(F_{15}\right)$. Communication misunderstandings include communication misunderstandings between tugboats and the shore, between ships, between tugboat operators and pilots, or a communication failure causing tugboat operators to take wrong actions, or failure to avoid an emergency, resulting in a collision crisis.

2. The second risk dimension is "ship hull/machine equipment $\left(D_{2}\right)$," which refers to errors caused by the misplaced interface between tugboat operators and ship hull/machine. Five risk factors $[9,10,2,8,20,21]$ can be summed to measure the "ship hull/machine equipment" dimension, as follows:

- Negligence of the relative motion between tugboats and commercial ships $\left(F_{21}\right)$. When tugboats assist commercial ships in and out of the dock, and tugboat operators neglect the relative motion of commercial ships; for the right-hand fixed-pitch propeller monocoque, due to the lateral force of the propeller, the ship will decelerate, while the stem will deflect to the right (the stern will deflect to the left of the ship). The larger the displacement, the larger the deflection angle of the stem or the stern, which leads to ship collision crisis during tugboat operations.

- Misevaluation of tugboat characteristics $\left(F_{22}\right)$. Tugboat operators are not familiar with or alert to the machinery efficiency and performance, rudder effect, and inertia of tugboats. Thus, they fail to take necessary emergency response measures in emergency situations, which amplifies the risk factors.

- Poor tugboat cable condition $\left(F_{23}\right)$. The tension of a tugboat's cable is not tested regularly; whether the breaking tension of the cable is maintained within the safe value cannot be confirmed, and the cable breaks during operations and leads to accident.

- Aging of tugboats $\left(F_{24}\right)$. When tugboats are too old, the equipment is frequently faulty, the safety factor of the hull structure is reduced, and the operational performance is poor, which amplifies the risk factors during operations.

- Poor machinery maintenance $\left(F_{25}\right)$. The tugboat equipment is not properly maintained, such as main engine, steering gear, air compressor, or winch, thus, leading to accidents due to dangerous factors during operations.

3. The third risk dimension is "environment $\left(D_{3}\right)$," which refers to the errors caused by a misplaced interface between tugboat operators and the environment. Four risk factors $[9,10,2,8,20,21]$ can be summed to measure the "environment" dimension, as follows:

- Narrow water areas in the working docks $\left(F_{31}\right)$. Due to the narrow water areas in some working docks of the first and second harbor of Kaohsiung port, the negligence of tugboat operators result in accidents due to insufficient space during operations.

- High traffic density of navigation channels $\left(F_{32}\right)$. The traffic density of the port is high, and the traffic flow is complicated. The probability of accidents caused by poor traffic environment is relatively increased.

- Negligence of the current weather impact $\left(F_{33}\right)$. Tugboat operators often evaluate the natural environment based on past experience, such as the hazards of wind and current on operational safety, but make misevaluation, thus, causing accidents during operations.

- Environmental judgment error $\left(F_{34}\right)$. Tugboat operators are not familiar with their surrounding environment leading to misjudgment or negligence, failing to react in real time, or making an incorrect response. Therefore, while tugboat operators consider the operations safe, an actual crisis may still exist.

\section{Method}

The analytic hierarchy process (AHP) method [16] is employed to evaluate the relative weights of key risk factors influencing harbor tugboat operations for Kaohsiung port in this paper. The steps are briefly summarized as follows. 
Step 1. Constructing the risk evaluation dimensions and risk factors.

The evaluation criteria (i.e., risk evaluation dimensions and risk factors in this paper) are the measure of decision making, and the construction of evaluation criteria can specify the problem to be evaluated. Hence, the construction of the risk evaluation dimensions and risk factors influencing harbor tugboat operations for Kaohsiung port is the most important step to evaluate the relative weights in this paper. Three risk evaluation dimensions and 14 risk factors are listed and described in Section 2. By the way, the AHP method employs an assessment system with a hierarchical structure to evaluate the research issues. The hierarchical framework diagram shown in Fig. 1.

Step 2. Establishing the pair-wise comparison matrices for all risk evaluation dimensions and risk factors.

The evaluation scales of AHP method (as shown in Table 1) are used to evaluate the relative importance for all risk evaluation dimensions and risk factors. The pair-wise comparison matrices can be then established.

Assume there are $j$ scholars or experts $\left(H_{1}, \ldots, H_{h}, \ldots, H_{j}, h=1,2, \ldots, j\right)$ in a committee. These experts are responsible for evaluating relative importance of $n$ risk evaluation dimensions $\left(D_{1}, \ldots, D_{t}, \ldots, D_{n}\right)$ and relative importance of $p$, $\ldots, q, \ldots$, and $r$ risk factors $\left(F_{11}, \ldots, F_{1 p}, \cdots, F_{t 1}, \ldots\right.$, $\left.F_{t q}, \cdots, F_{n 1}, \ldots, F_{n r}\right)$ under each risk evaluation dimension $\left(D_{t}, t=1,2, \ldots, n\right)$.

Letting $d_{t k}^{h}, h=1,2, \ldots, j, \forall t, k=1,2, \ldots, n$, is relative importance for risk evaluation dimension $D_{t}$ to $D_{k}$ given by the scholar or expert $H_{h}$. The pairwise comparison matrix $M^{h}$ of relative importance for risk evaluation dimensions $D_{t}$ and $D_{k}$ given by the scholar or expert $H_{h}$ can be built as follows:

$M^{h}=\left[d_{t k}^{h}\right]_{n \times n}$

where $d_{t k}^{h}=1, \quad \forall t=k ;$ and $d_{t k}^{h}=1 / d_{k t}^{h}, \quad \forall t \neq k$.

We use the same process, the pair-wise comparison matrices for relative importance of $p, \ldots, q, \ldots$,

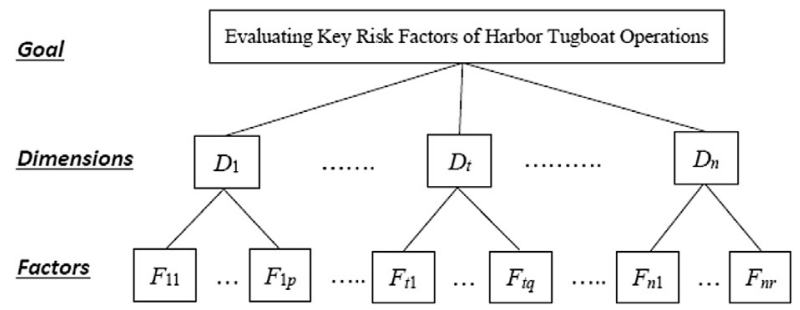

Fig. 1. Hierarchical structure of this research issue.
Table 1. The evaluation scales of AHP method.

\begin{tabular}{|c|c|c|}
\hline $\begin{array}{l}\text { Intensity of } \\
\text { importance }\end{array}$ & Definition & Explanation \\
\hline 1 & Equal importance & $\begin{array}{l}\text { Two activities contribute } \\
\text { equally to the objective }\end{array}$ \\
\hline 3 & $\begin{array}{l}\text { Weak importance } \\
\text { of one over another }\end{array}$ & $\begin{array}{l}\text { Experience and judgment } \\
\text { slightly favour one activity } \\
\text { over another }\end{array}$ \\
\hline 5 & $\begin{array}{l}\text { Essential or strong } \\
\text { importance }\end{array}$ & $\begin{array}{l}\text { Experience and judgment } \\
\text { strongly favour one } \\
\text { activity over another }\end{array}$ \\
\hline 7 & $\begin{array}{l}\text { Very strong or } \\
\text { demonstrated } \\
\text { importance }\end{array}$ & $\begin{array}{l}\text { An activity is favoured } \\
\text { very strongly over } \\
\text { another; its dominance } \\
\text { can be demonstrated in } \\
\text { practice }\end{array}$ \\
\hline 9 & Absolute importance & $\begin{array}{l}\text { The evidence favouring } \\
\text { one activity over another } \\
\text { is of the highest possible } \\
\text { order of affirmation }\end{array}$ \\
\hline $2,4,6,8$ & $\begin{array}{l}\text { Intermediate values } \\
\text { between adjacent } \\
\text { scale values }\end{array}$ & $\begin{array}{l}\text { When compromise is } \\
\text { needed }\end{array}$ \\
\hline
\end{tabular}

Source: Saaty [16].

and $r$ risk factors $\left(F_{11}, \ldots, F_{1 p}, \cdots, F_{t 1}, \ldots, F_{t q}, \cdots\right.$, $\left.F_{n 1}, \ldots, F_{n r}\right)$ under each risk evaluation dimension $\left(D_{t}, t=1,2, \ldots, n\right)$ given by the scholar or expert $H_{h}$ can be constructed, too.

Step 3. Consistency testing

Consistency testing is an important step in the AHP method. It can be performed by using the consistency ratio (C.R.), which is defined as:

C.R. $=\frac{\text { C.I. }}{\text { R.I. }}$

where C.I. value and R.I. value denote the consistency index and random index, respectively. And

C.I. $=\frac{\lambda_{\max }^{h}-n}{n-1}$

where $n$ is the number of the risk evaluation dimensions compared, and $\lambda_{\max }^{h}$ is the eigenvalue of pair-wise comparison matrix $M^{h}=$ $\left[d_{t k}^{h}\right]_{n \times n}$.

The $\lambda_{\max }^{h}$ herein is computed by the following steps: (1) Compute the weight $w_{t}^{h}$ of the risk evaluation dimension $D_{t}$.

$$
\begin{aligned}
w_{t}^{h} & =\left(\prod_{k=1}^{n} d_{t k}^{h}\right)^{1 / n} / \sum_{t=1}^{n}\left(\prod_{k=1}^{n} d_{t k}^{h}\right)^{1 / n}, \\
t & =1,2, \ldots, n ; h=1,2, \ldots, j .
\end{aligned}
$$

(2) Compute the eigenvalue $\lambda_{\max }^{h}$ of pair-wise comparison matrix $M^{h}=\left[d_{t k}^{h}\right]_{n \times n}$. 
Table 2. The R.I. value.

\begin{tabular}{llllllll}
\hline $\mathrm{N}$ & 1 & 2 & 3 & 4 & 5 & 6 & 7 \\
\hline R.I. & 0.00 & 0.00 & 0.58 & 0.90 & 1.12 & 1.24 & 1.32 \\
\hline Source: Saaty [16].
\end{tabular}

$\lambda_{\max }^{h}=\left(\frac{1}{n}\right)\left(\sum_{t=1}^{n}\left(\sum_{k=1}^{n} d_{t k}^{h} w_{k}^{h} / w_{t}^{h}\right)\right)$

The R.I. value can be obtained from Table 2. When the C.R. value is less than or equal to 0.1 , the consistency test is acceptable [16].

Step 4. Computing the weights of all risk evaluation dimensions and risk factors

Suppose there are $g \leq j$ scholars or experts whose evaluation results pass the consistency test. Letting $b_{t k}^{i}, i=1,2, \ldots, g ; \forall t, k=1,2, \ldots, n$, be the relative importance for risk evaluation dimension $D_{t}$ to $D_{k}$ given by the scholar or expert $H_{i}$. Then the pair-wise comparison matrix $B$ of the relative importance for all risk evaluation dimensions given by all $g$ scholars or experts can now be built as follows:

$B=\left[b_{t k}\right]_{n \times n}$

where $b_{t k}=\left(\prod_{i=1}^{g} b_{t k}^{i}\right)^{1 / g}$ if $t<k ; b_{t k}=1, \forall t=k ; b_{k t}=$
$1 / b_{t k}, \forall t \neq k$.

Letting $w=\left(w_{1}, w_{2}, \ldots, w_{t}, \ldots, w_{n}\right)$ be the eigenvector of the pair-wise comparison matrix $B=$ $\left[b_{t k}\right]_{n \times n}$, then, the weight $w_{t}$ of the risk evaluation dimension $D_{t}$ can obtain by

$w_{t}=\left(\prod_{k=1}^{n} b_{t k}\right)^{1 / n} / \sum_{t=1}^{n}\left(\prod_{k=1}^{n} b_{t k}\right)^{1 / n}, t=1,2, \ldots, n$.

We employ the same process, the pair-wise comparison matrices of relative importance between $p, \ldots, q, \ldots$, and $r$ risk factors $\left(F_{11}, \ldots, F_{1 p}, \cdots\right.$, $\left.F_{t 1}, \ldots, F_{t q}, \cdots, F_{n 1}, \ldots, F_{n r}\right)$ under each risk evaluation dimension $\left(D_{t}, t=1,2, \ldots, n\right)$ given by all $g$ scholars or experts whose evaluation results pass the consistency testing can be built. Then, the weights of all risk factors can be obtained using the similar steps.

Step 5. Computing the integrated weights for each risk factor

Letting $w_{t}, \forall t=1,2, \ldots, n$, be the weight of the risk evaluation dimension $D_{t}$. Letting $w_{u}, \forall u=1,2$, $\ldots, p ; \cdots ; \quad \forall u=1,2, \ldots, q ; \cdots ; \quad$ and $\forall u=$ $1,2, \ldots, r$, be the weights of $p, \ldots, q, \ldots$, and $r$ risk factors. The integrated weights of each $p, \ldots, q, \ldots$, and $r$ risk factor can be denoted as

$G_{u}=w_{t} \times w_{u}, t=1,2, \ldots, n$.

$$
\begin{gathered}
\forall t=1,2, \ldots, n ; \forall u=1,2, \ldots, p ; \cdots ; \\
\forall u=1,2, \ldots, q ; \cdots ; \text { and } \forall u=1,2, \ldots, r,
\end{gathered}
$$

\section{Empirical study}

In this section, an empirical study to evaluate key risk factors influencing harbor tugboat operations for Kaohsiung port is performed as follows.

\subsection{Data collection and results}

The AHP expert questionnaire adopted in this study organizes the three risk evaluation dimensions and 14 important risk factors in Section 2, which are taken as the basis for the pairwise comparison matrix. To confirm whether the text or grammar contents of the AHP questionnaire are clear enough, or any content of the risk factors is missing, this study conducted pre-tests on five shipping scholars and tugboat captains. Finally, the expert questionnaire was revised twice, as based on these experts and scholars, to form the formal AHP expert questionnaire.

In this study, the relative weights of the risk factors influencing the harbor tugboat operations for Kaohsiung port were evaluated through the AHP expert questionnaire, in order to identify the key risk factors influencing harbor tugboat operations. In addition, the tugboat captains of Kaohsiung port and the officers in charge of the Maritime and Port Bureau (MPB) were invited to fill out the AHP expert questionnaire. The questionnaires were mainly distributed by mail and direct interviews. For direct interviews, the authors aided the experts in filling out the questionnaires to check the consistency of the questionnaires filled out by the experts, and thus, increased the proportion of valid questionnaires. Regarding the judgment of questionnaire validity, as based on the operational process of AHP method, this study confirmed that if the C.I. value is lower than or equal to 0.1 [16], the pairwise comparison matrix is consistent, which shows that the expert judgment results are consistent, and the questionnaires are regarded as valid. It is worth mentioning that the AHP method must determine whether the pairwise comparison matrix is a consistency matrix for the consistency verification. If a pairwise comparison matrix that does not conform to the consistency, the expert's judgment is 
inconsistent. At this time, the expert must re-evaluate the pairwise comparison matrix until the consistency requirement is met. Due to the cumbersome process of the AHP expert questionnaire survey, it is the best situation for the assessor to directly interview in practical applications. This is because direct interviews can assess the consistency of expert judgments on the spot, making each questionnaire an effective questionnaire.

A total of 24 questionnaires were distributed, and 23 valid questionnaires were recovered. As Robbins [15] suggested, the number of experts required for group decision-making problems should be 5-7, and a total of 23 valid questionnaires were recovered in this study. Thus, the valid recovered questionnaires should therefore be acceptable and sufficient to provide a representative range of views. In addition, the basic information of the 23 respondents of this AHP questionnaire is as follows: (1) the main respondents are the Taiwan International Ports Corporation, Ltd. (TIPC) $4.4 \%$, the MPB $47.8 \%$, the TIPC Marine Corporation Ltd. $34.8 \%$, and the private marine ship service company $13 \%$; (2) the ages 31 to 40 years old account for the majority of $47.8 \%$, followed by 51 to 60 years old $21.8 \%$; (3) working years are mostly 5 to 10 years, accounting for $52.1 \%$, followed by 11 to 15 years accounting for $30.4 \%$; and (4) job titles 'Others' (i.e., Port State controller of the South Maritime Affairs Center of the MPB) accounted for the majority of $47.8 \%$, followed by the captain of $34.8 \%$.

In this paper, the data was acquired from 23 valid expert questionnaires; through the calculation steps in Section 3, this study applied Expert Choice software to calculate the weights of the risk evaluation dimensions and risk evaluation factors. The weights analysis and ranking results are shown in Table 3.
The findings of empirical study in Table 3 are explained as follows:

1. 'Tugboat operators (0.576),' ranking 1 , was the most important risk evaluation dimension influencing harbor tugboat operations for Kaohsiung port. The risk evaluation dimension of 'ship hull/machine equipment (0.227)' was ranked in the second place, while 'environment (0.197)' was the lowest ranked.

2. In the 'tugboat operators' dimension, the "judgment error" factor was the most important in terms of normalized weight. In the 'ship hull/ machine equipment' dimension, "negligence of the relative motion between tugboats and commercial ships" was the most important risk factor. In the 'environment' dimension, "environmental judgment error" was the most important risk factor.

3. Daniel [3] believed that most industries have two to six key factors for success, and if a company wants to succeed, it must pay particularly adequate attention to these factors. This study believes that the weight of each risk factor must be higher than the average weight of all risk factors (1/14 or 0.071$)$, which is more meaningful in the selection of key indicators. Therefore, in the selection of key risk factors, the weights of the first six risk factors must be higher than 0.0714. And the total weight of the six key risk factors is as high as 0.650 . Finally, six risk factors were selected as the key risk indicators. The results showed that the six most important risk factors by integrated weights are located in the 'tugboat operators' dimension and 'ship hull/ machine equipment' dimension. There are five key risk factors in the 'tugboat operators'

Table 3. The weights for all risk evaluation dimensions and risk factors.

\begin{tabular}{|c|c|c|c|c|}
\hline $\begin{array}{l}\text { Risk evaluation } \\
\text { dimensions }\end{array}$ & $\begin{array}{l}\text { Normalized/Integrated } \\
\text { weight }(\mathrm{A})\end{array}$ & Risk factors & $\begin{array}{l}\text { Normalized } \\
\text { weight (B) }\end{array}$ & $\begin{array}{l}\text { Integrated } \\
\text { weight }(C)=(A) *(B)\end{array}$ \\
\hline \multirow[t]{5}{*}{ Tugboat operators } & $0.576(1)$ & Work fatigue & $0.236(2)$ & $0.136(2)$ \\
\hline & & Judgment error & $0.288(1)$ & $0.166(1)$ \\
\hline & & Poor skills & $0.207(3)$ & $0.119(3)$ \\
\hline & & Personality factors & $0.125(5)$ & $0.072(6)$ \\
\hline & & Communication misunderstanding & $0.144(4)$ & $0.083(4)$ \\
\hline \multirow[t]{5}{*}{$\begin{array}{l}\text { Ship hull/machine } \\
\text { equipment }\end{array}$} & $0.227(2)$ & $\begin{array}{l}\text { Negligence of the relative motion } \\
\text { between tugboats and commercial ships }\end{array}$ & $0.327(1)$ & $0.074(5)$ \\
\hline & & Misevaluation of tugboat characteristics & $0.185(3)$ & $0.042(11)$ \\
\hline & & Poor tugboat cable condition & $0.154(4)$ & $0.035(13)$ \\
\hline & & Aging of tugboats & $0.130(5)$ & $0.030(14)$ \\
\hline & & Poor machinery maintenance & $0.204(2)$ & $0.046(10)$ \\
\hline \multirow[t]{4}{*}{ Environment } & $0.197(3)$ & Narrow water areas in the working docks & $0.244(3)$ & $0.048(9)$ \\
\hline & & High traffic density of navigation channels & $0.201(4)$ & $0.040(11)$ \\
\hline & & Negligence of the current weather impact & $0.274(2)$ & $0.054(8)$ \\
\hline & & Environmental judgment error & $0.281(1)$ & $0.055(7)$ \\
\hline
\end{tabular}


dimension, including "judgment error," "work fatigue," "poor skills," "communication misunderstanding," and "personality factors," respectively. On the 'ship hull/machine equipment' dimension, there is only a key risk factor of "negligence of the relative motion between tugboats and commercial ships." Moreover, among the six key risk factors, the relative weights of the first three risk factors are all higher than 0.1, indicating that the top three key risk factors are particularly significant for the harbor tugboat operations of Kaohsiung port.

\subsection{Discussions of the mitigation of key risk factors}

\subsubsection{Concepts of risk control strategies}

In the risk management process, appropriate risk management strategies should be implemented to mitigate the risks after risk evaluation for the purpose of reducing the uncertainty with reasonable costs, and ensuring that the expected result is acceptable to the risk taker. The main concept of risk control can be divided into risk prevention and risk reduction, where the former aims to reduce the frequency of risks, while the latter aims to reduce the impacts of risks. The main risk control strategies are avoidance, risk prevention, risk reduction, risk segregation and risk transfer. The main concepts are described as follows:

- Avoidance. It focuses on the zero probability of loss. It is targeted for specific risks, and refers to avoiding the threat of risks after risk evaluation, or completely abandoning the original idea or behavior if unavoidable. When both the frequency and severity of risks are high, the avoidance strategy is applicable. Alternatively, when the implementation costs of other risk management measures are too high, the avoidance strategy is also recommended.

- Risk prevention. It refers to taking preventive measures to reduce the possibility of risk loss, and thus, aims to reduce the frequency of risk loss. The main practice of risk prevention is to change the characteristics and environments of risk factors, as well as the mechanisms by which risk factors interact with the environment under feasible conditions.

- Risk reduction. It refers to the measures taken to reduce the degree or severity of loss when a risk event occurs. The purpose of risk reduction is twofold, it minimizes the risk loss when a risk occurs and controls measures after the risk occurs to reduce the degree of risk loss.

- Risk segregation. It is also known as risk share. It aims to subdivide the loss unit to smaller units and reduce the concentration of economic units, thus, facilitating risk control and management, or reducing the dependence of economic units on specific objects or individuals. Risk segregation can be further divided into separation and reserve.

(1) Separation. It refers to separating existing single assets or operational processes into different projects or procedures. However, separation may increase the frequency of loss, and whether the loss of expectation is reduced depends on the frequency and magnitude of risk loss.

(2) Reserve. It refers to preparing the duplicates or backup plans of backup assets and important document files, or technical personnel training reserves. Reserve does not affect the frequency of loss, and thus, can reduce the expected loss.

- Risk Transfer. The risk transfer in risk control is different from insurance. It refers to a contractual act that transfers the risk to the non-insured economic individual, and subjects such economic individual to the obligation or loss. The transferor does not intent to obtain financial compensation from the transferee, meaning it is about the transfer of responsibility. In other words, the transferee not only undertakes the legal liability of risks, but may also suffer the loss of assets caused by the risk accident.

\subsubsection{Adopted risk control strategies}

This study believes that, in the event of a risk accident, a series of effective control measures should be proposed to address such risks, and specific recommendations should be made to provide a reference for the harbor tugboat operations risk of Kaohsiung port, thereby, enhancing the operational safety of tugboats. Therefore, based on the first six key risk factors, the risk management strategy is proposed, as follows:

- Judgment error. In practice, tugboat operators may make judgment errors due to personal emotions, such as physical illness, financial problems, family death or illness, and marriage. In addition, tugboat operators may lack danger awareness, meaning they cannot handle issues 
properly when problems occur, thus, missing the best handling time window and leading to damage. Therefore, in response to this risk, this paper suggests that reserve and avoidance strategies in risk management should be adopted. During driver dispatch, a senior driver, who can take over the ship in case of accidents, with abundant experience should be added when tugboat operators are unable to drive normally due to personal problems. In normal times, senior drivers may properly assist another younger drivers in operations, and provide experience to prevent accidents.

-Work fatigue. Due to the high ship entry and exit volume of Kaohsiung port, the burden on harbor tugboat operations is heavy, and must provide work shifts 24 hours a day all year round. The current length of exhausting shifts make many drivers fatigued, and because they are subjected to irregular working hours, overtime work, abnormal work and rest balance, excessive pressure, excessive fatigue, and lack of concentration, it leads to accidents. In response to this risk, this paper suggests that avoidance and prevention strategies in risk management should be adopted. In addition to avoiding overtime work, the dispatch of all crew members should meet the minimum working conditions of the Labor Law, thus, providing tugboat crews with enough time to rest and reduce their fatigue. At the same time, a wake-up device should be installed on the joystick of the bridge to prevent the driver from falling asleep during work.

- Poor skills. Tugboat operators may have poor driving skills due to a lack of learning willingness or on-the-job training. Meanwhile, personnel rotation may also result in insufficient operational experience, and drivers cannot effectively improve their ship operations skills. In response to this risk, this paper suggests that control and prevention strategies in risk management should be adopted. In other words, new drivers should start with low-horsepower services to accumulate a considerable number of ship operations hours, and then, gradually proceed to high-horsepower tugboat operations services, in order to reduce the losses arising from the failure to take emergency measures in the case of an accident due to poor skills. In addition, driver performance should be evaluated. If hull damage or marine accidents are caused by improper human operations, the case will be included in the annual evaluation records, in order that the drivers can be more careful in their future operations, and thus, reduce the frequency of accidents.

- Communication misunderstanding. When working on a tugboat, tugboat operators must always have clear and detailed communication with the ships, the shore, and the pilots, in order to carry out the pulling and pushing work. In case of any communication misunderstanding between the ships and the shore, or between the ships and the pilots, or general communication failure, tugboat operators may take the wrong action, or fail to avoid an emergency in time, which in turns leads to collision or other marine accidents. In response to this risk, this paper suggests that prevention and reserve strategies in risk management should be adopted. In order to prevent the occurrence of communication misunderstanding, the tugboat drivers must repeat their instructions after receiving them from the pilots, and if there is any doubt or ignorance of the instructions. The tugboat drivers should reconfirm with the pilots. Regarding the risk of communication failure, when the tugboat drivers switch from the duty channel to the designated work channel of the pilots, the tugboat drivers should mark the work channel on the self-storing report. Regarding the reserve strategy, it is recommended to simultaneously open three VHF radiotelephones; where one channel is switched to the port signal station, one channel is reserved as the duty channel, and one channel is switched to the designated work channel of the pilots to ensure that if any VHF faults occur, other non-current phones can be used to prevent communication loss.

- Personality factors. From expert interviews, it is known that the personality factors of tugboat operators, such as arrogance, irritability, suspicion, anxiety, and tension, make operators more prone to accidents, and such operators cannot handle an emergency calmly or avoid the expansion of loss. In response to this risk, this paper suggests that a risk prevention strategy should be adopted. During driver recruitment, personality orientation testing should be conducted first, which focuses on the characteristics of carefulness, prudence, and anti-stress as the basis for personnel selection.

- Negligence of the relative motion between tugboats and commercial ships. When tugboats 
assist commercial ships in entry and exit, if the fast container ships is docked to the designated dock, the pilots will use the half-astern or full astern to slow or stop the commercial ships. At this point, the stem of the commercial ships will deflect heavily to the right (the stern heavily to the left) at a high speed. At the same time, pilots will request tugboats to adhere to the left stern of commercial ships and prepare to push. If the draught of light cargo container ships is shallow, and the stern deflection is high, the tugboats must arrive between the bridge and the stern, or even under the bridge, in order to perform pushing operations. In this situation, if the relative motion between the two ships are neglected, tugboats will often collide with commercial ships. In response to this risk, this paper suggests that risk reduction and prevention strategies should be adopted. Regarding the reduction strategy, new drivers should start from low-horsepower tugboat services to high-horsepower tugboat services, in order to control losses in the case of accidents. Regarding the risk prevention strategy, the education and training of new drivers should be strengthened, while senior drivers should regularly teach new drivers ship operation and navigation skills to prevent accidents.

In summary, this paper simplifies the six key risk factors of harbor tugboat operations as well as its risk strategy attributes, as shown in Table 4. It is suggested that these risk strategies can be applied to the tugboat operations of Kaohsiung port, and these risk strategies can also be widely applied by various industries.

\section{Concluding remarks}

Harbor tugboat operations pose certain operational risks for ship entry and exit, as well as

Table 4. The adopted strategies for key risk factors.

\begin{tabular}{ll}
\hline Key risk factors & Adopted risk strategies \\
\hline Judgment error & - Reserve \\
& - Risk prevention \\
Work fatigue & - Avoidance \\
& - Risk prevention \\
Poor skills & - Avoidance \\
& - Risk reduction \\
Communication & - Reserve \\
misunderstanding & - Risk prevention \\
Personality factors & - Risk prevention \\
Negligence of the relative & - Risk reduction \\
$\quad$ motion between tugboats & \\
and commercial ships & \\
\hline
\end{tabular}

docking operations. Accidents arising from unsafe harbor tugboat operations will affect the performance and competitiveness of the port. In addition, Kaohsiung port is the most dangerous area for international commercial port navigation in western Taiwan. In order to build a safe harbor tugboat operation environment for Kaohsiung port, harbor tugboat operations practitioners should strengthen their risk management to maintain the loading and unloading safety of ships. Hence, this study conducts in-depth interviews on the actual practitioners of harbor tugboat operations, and then, analyzes the risk factors that may cause cargo damage in each operational phase of harbor tugboat operations through the risk management evaluation process. In summary, the main purpose of this paper is to evaluate key risk factors influencing the harbor tugboat operations for Kaohsiung port.

At first, a total of three evaluation dimensions with 14 preliminary risk factors are conducted from literature and interviews of tugboat captains. With regards to evaluate key risk factors, an empirical survey using the AHP method has been performed. The empirical results show that: The top six key risk factors influencing the harbor tugboat operations for Kaohsiung port are "judgment error," "work fatigue," "poor skills," "communication misunderstanding," "negligence of the relative motion between tugboats and commercial ships," and "personality factors," respectively. In addition, most of these key risk factors are located in the 'tugboat operators' dimension, especially the weight of the top three key risk factors is as high as $42.1 \%$. The results of the study indicate that the tugboat operation practitioners at Kaohsiung port should pay special attention to the first three key risk factors of the 'tugboat operators' dimension to facilitate the management of the safe operation activities.

"Judgment error" has the largest weighting value in the evaluation of the 14 risk factors. It should be noted that the harbor tugboat operations of Kaohsiung port should pay special attention to whether tugboat operators are subjected to personal problems or lack crisis sense, which would lead them to make judgment errors in the face of problems. According to expert interviews, the reason for the high risk factor of the Taiwan International Ports Corporation, Ltd. (TIPC) which was established after the restructuring of the Port Authority, is that it has been recruiting younger practitioners. Therefore, this study suggests that during the dispatch of tugboat crews, an experienced driver should be assigned to work with another younger driver to facilitate timely assistance and operational experience. 
Secondly, "work fatigue" ranked second in the evaluation of the 14 risk factors. The Kaohsiung port is the largest international commercial port in Taiwan, and an average of 100 ships enter and leave the port every day. Therefore, the volume of the harbor tugboat operations far exceed that of other international commercial ports in Taiwan, and tugboat practitioners should not ignore the work fatigue of harbor tugboat operators. As harbor tugboat operations are year round services, and serve both inbound and outbound ships in a work shift manner, excessively intensive work shifts will exhaust the tugboat captains. The impact of such fatigue is very dangerous for ship operations, as fatigue will affect the thinking and behavior of drivers, as well as their ability to judge or solve complex problems. Therefore, the drivers should be given adequate rest to reduce the frequency of accidents, which will reduce operating losses and improve the international image of Kaohsiung port as a safe port.

Finally, "poor skills" ranked third in the evaluation of the 14 risk factors. Since Kaohsiung port is the main port in the Asia-Pacific region, and the number, size, and speed of ships in the world have increased significantly. It brings many new technical requirements for harbor tugboat operations. If the drivers lack on-the-job training or experience, a slight mistake may result in a marine accident. Therefore, this study suggests that inexperienced drivers should start from low-horsepower services to accumulate a considerable number of ship operations hours, and then, gradually proceed to highhorsepower tugboat operations services. Meanwhile, a driver evaluation system should be established. If hull damage or a marine accident is caused by improper human operations, the case will be included in the annual evaluation records as a reference for future rewards and punishments. It is hoped that drivers can operate tugboats more carefully to prevent accidents.

In addition, this study only evaluates key risk factors, and has not yet evaluated the above risk management strategies. Therefore, this study suggests that harbor tugboat companies should review the feasibility of risk evaluation strategies, analyze each risk management strategy through cost-benefit analysis in the future, and review and implement risk strategies with benefits greater than cost to effectively dispatch and apply risk management strategies under limited resources.

\section{References}

1 Chen YJ. A study of service quality and customer satisfaction of harbor tug for carrier - A case of Taipei Port. Master Thesis. National Taiwan Ocean University; 2010.

2 Chou CC, Su YL, Li RF, Tsai CL, Ding JF. Key navigation safety factors in Taiwanese harbors and surrounding waters. J Marine Sci Technol 2015;23(5):685-93.

3 Daniel DR. Management information crisis. Harvard Business Rev 1961;39(5):111-21.

4 Das B, Tejpal N. A computer simulation approach to improving tugboat shipbuilding design and development productivity. J Ship Prod 2008;24(4):221-7.

5 Ding JF, Kuo JF, Shyu WH, Chou CC. Evaluating determinants of attractiveness and their cause-effect relationships for container ports in Taiwan: Users' perspectives. Marit Pol Manag 2019;46(4):466-90.

6 Ding JF, Tseng WJ. Fuzzy risk assessment on safety operations for exclusive container terminals at Kaohsiung port in Taiwan. J Eng Marit Environ 2013;227(2):208-20.

7 Fallahzadeh M, Kiani M, Talebnezhad H. Evaluating safety control criteria in maritime traffic using formal safety assessment. Case study: Iranian Port; Bushehr. J Marit Res 2015; 12(3):37-48.

8 Faturachman D, Mustafa S. Performance of safety sea transportation. Proc - Soc Behav Sci 2012;57:368-72.

9 Hsu WK. Ports' service attributes for ship navigation safety. Saf Sci 2012;50(2):244-52.

10 Hsu WK. Assessing the safety factors of ship berthing operations. J Navig 2015;68(3):576-88.

11 Kolanović I, Dundović Č, Jugović A. Customer-based port service quality model. Promet - Traffic Transport 2011;23(6): 495-502.

12 Lin JM. An application of fuzzy MCDM technique on the study of major Taiwanese harbour tugs operational productivity. Master Thesis. National Taiwan Ocean University; 2005.

13 Lioa KC, Wu CC, Hsiao YC. An analysis of the key human factor in collision accident on maritime casualty - Application analytic hierarchy process. Maritime Quart 2006;15(4):67-93.

14 Liu CP, Liang GS, Su Y, Chu CW. Navigation safety analysis in territorial waters of ports. J Navig 2006;59(2):201-11.

15 Robbins SP. Management. New Jersey: Prentice Hall; 1994.

16 Saaty TL. The analytic hierarchy process. New York: McGrawHill Companies, Inc; 1980.

17 Song DW, Panayides PM. Maritime logistics: A complete guide to effective shipping and port management. London, UK: Kogan Page Limited; 2012.

18 Tseng WJ, Ding JF, Hung SH, Poma W. Risk management of terminal on-site operations for special bulk cargos in Taiwan. Int J Marit Eng 2019;161(A2):117-28.

19 Verhoeven P. A review of port authority functions: Towards a renaissance? Marit Pol Manag 2010;37(3):247-70.

20 Wang HC, Lee HS. The impact of navigation safety in Kaohsiung harbor. J Marine Eng Technol 2012a;11(1):45-50.

21 Wang HC, Lee HS. Evaluating navigation safety for harbours in Taiwan: An empirical study. J Marine Eng Technol 2012b; 11(3):31-7.

22 Wang HN. The study on the factors of the operational efficiency of tug - Case study of Mailiao Harbor. Master Thesis. National Taiwan Ocean University; 2009.

$23 \mathrm{Xu} \mathrm{Q}$, Mao J, Jin Z. Simulated annealing-based ant colony algorithm for tugboat scheduling optimization. Math Prob Eng 2012:22. 2012, Article ID 246978.

24 Yip TL. Port traffic risks - A study of accidents in Hong Kong waters. Transport Res Part E: Logist Transport Rev 2008;44(5): 921-31. 